\title{
Do Chinese Stock Markets React To The Newspaper Recommendations?
}

\author{
Francis Cai, (Email: caif@wpunj.edu), William Paterson University of New Jersey \\ Lianzan Xu, (Email: xul@wpunj.edu), William Paterson University of New Jersey \\ C.K. Leung, (Email: leungc@wpunj.edu), William Paterson University of New Jersey \\ Huifang Cheng (Email: chfb@mail.hz.zj.cn), Zhejiang University of Technology, China
}

\begin{abstract}
This paper studies how the stock prices in Chinese stock markets react to the stock recommendations from a Chinese business newspaper Zhong Guo Zheng Quan Bao (China Security). Using event study methodology and market model as a benchmark, we calculate abnormal returns to ascertain the impact of published recommendations. We find that there are no statistically significant long-term abnormal returns associated with the published recommendations. However, there are profitable opportunities if investors act prior to the published recommendations. We also find that the recommendations from the newspaper causes a significant short term movement two days after the publication day, suggesting a delayed response from the investors who act on the recommendation. The delayed response shows the gradual dissemination of the information in Chinese stock markets. In summary, these results indicate that press recommendations of Chinese stocks contain no useful economic information for investors who act on the published recommendations. The possible abnormal returns for investors who buy the stocks before the recommendations are made public are evidence of a market that is strong-form inefficient and the delayed response from investors to the newspaper recommendations is most likely the evidence of a market that is semi-strong-form inefficient.
\end{abstract}

\section{Introduction}

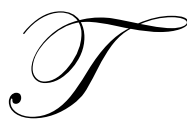

his paper empirically investigates the impact of the stock recommendations from a Chinese business newspaper Zhong Guo Zheng Quan Bao (China Security). We will test whether investors can make abnormal trading profits by following the newspaper recommendations in CS. The efficient market hypothesis (EMH) holds that stock prices fully reflect all available information at all times. This especially applies to publicly available information and suggests that published stock 'tips' cannot provide abnormal returns to investors acting on them. If they did, that would imply that tips supply new information not previously available to the market.

However, published stock recommendations from brokerage houses, security analysts, and investment news letters abound in stock markets worldwide. Not only do security analysts believe they can earn superior returns, ${ }^{1}$ but also some academic researchers suggest that superior returns are possible. Stickel (1995) show positive returns on stock recommendations. Womack (1996) shows the brokerage analysts' recommendations have investment value. Similar positive findings can also be found in Palmon, Sun and Tang (1994); Wijmenga (1990); Syed, Liu and Smith (1989). Barber, Lehavy, Mcnichols, and Trueman (2001) document that investment strategies based on the consensus recommendations, in conjunction with active portfolio management yield annual abnormal returns greater than four percent.

The finance and acco

unting literature is replete with the studies of stock price reaction to the analysts' recommendations. However most of these studies use the US stock market data. Few studies exist of emerging markets. A literature search found only Hong Kong, Singapore, and the Netherlands markets as examples of prior studies 
Readers with comments or questions are encouraged to contact the authors via email. of abnormal returns from published recommendations in emerging markets.

We analyze daily abnormal returns in the Stock Exchange of Shanghai and Senzhen resulting from published stock recommendations of the largest business newspaper in China Zhong Guo Zheng Quan Bao (China Security). Using the sample from January, 2001 to December, 2001, we examine how the stock prices in Chinese stock markets react to the stock recommendations. Using event study methodology and market model as a benchmark, we calculate abnormal returns to ascertain the impact of published recommendations. We find that there are no statistically significant long-term abnormal returns associated with the published recommendations. However, there are profitable opportunities if investors act prior to the published recommendations. We also find that the recommendations from the newspapers cause a significant short term movement two days after the publication day, suggesting a delayed response from the investors who act on the recommendation. The delayed response shows the gradual dissemination of the information in Chinese stock markets. In summary, these results indicate that press recommendations of Chinese stocks contain no useful economic information for investors who act on the published recommendations. The possible abnormal returns for investors who buy the stocks before the recommendations are made public are evidence of a market that is strong-form inefficient and the delayed response from investors to the newspaper recommendations is most likely the evidence of a market that is semi-strong-form inefficient.

Following Lawrence, Sun, and Cai (1996), we ask the following five questions in our paper:

(1) Do security prices on the Shanghai and Senzhen react to the recommendations published in CS?

(2) Is there any information leakage prior to the publication of share recommendations?

(3) Do the recommendations possess real economic content or permanence, or are they merely a 'self-fulfilling prophecy'?

(4) Can investors expect profit by following these recommendations?

(5) Why are significant positive and negative abnormal returns detected before and after publication?

The Plan of this paper is as follows. In section II, we present our data. Section III explains the model and methodology. The empirical results are analyzed in section IV. A summary and conclusions section ends the paper.

\section{The Sample Data}

The analyst recommendations used in this study are from Zhong Guo Zheng Quan Bao (China Security, CS thereafter). To test the impact of the publication of recommendations on abnormal returns, we define event day (day 0 ) as publication date. The period plus and minus 10 days surrounding the event day is the 'event window.'

Stock recommendations are published daily in the two nationally circulated business newspapers in China: China Security and Shanghai Security. However there is no existing database for the stock recommendations. We have to manually go over the newspaper for the data collection. Given the limited amount of the resources for this research we choose CS because it is the largest business newspapers in China.

The same stock might be recommended the same day from Shanghai Security. To overcome this "overlapping" issue, we check the stock recommendations in Shanghai Zheng Quan Bao (Shanghai Security, SS thereafter). If the same stock is also recommended in SS we will remove the stock from being selected into the sample. The other type of "overlapping" is the same stock recommendations in consecutive weeks from CS. We will exclude the stock if it is recommended in consecutive weeks.

Our sample includes recommendations from January 2001 to December 2001. Over a period of 12 months, a total of 120 recommendations were selected. We will only test the favorable recommendations since almost all the recommendations in Chinese newspapers are favorable recommendations.

The share data are obtained from Stockstar and Yahoo China. The stock sample includes stocks from communication industry, pharmaceutical industry, stocks from wine industry, stocks from chemical industry, retail 
industry, conglomerate, electronics industry, and financial industry. These stocks are representative of the Chinese stock market.

To use market model as a benchmark to calculate the abnormal return, we need market return data. We use Shanghai Composite Index for the market return proxy in our model. For the estimation of the market model, we use a history of two hundred daily returns before the event day to estimate the parameters of the market model.

\section{Model and Methodology}

We use market-and-risk-adjusted model to estimate the magnitude of share price adjustments (abnormal returns) each day of the event window. The model used in our paper is called market model which served as the basis for the pioneering event study conducted by Fama, Fisher, Jensen and Roll (1969). Later Brown and Warner (1980) found that this simple model was more powerful in terms of its ability to identify abnormal performance than any of the other, more complex risk-adjusted models available.

The market model used to estimate the abnormal return for the jth stock in period $t$ is as follows:

$\mathrm{R}_{\mathrm{j}, \mathrm{t}}=\alpha_{\mathrm{j}}+\beta_{\mathrm{j}} \mathrm{R}_{\mathrm{m}, \mathrm{t}}+\varepsilon_{\mathrm{j}, \mathrm{t}}$

Where

$R_{\mathrm{j}, \mathrm{t}} \quad=\quad$ return on security $j$ on day $t$

$R_{\mathrm{m}, \mathrm{t}}=\quad$ return on market on day $t$

$\alpha_{\mathrm{j}}=$ a constant over time, stable component of security returns

$\beta_{\mathrm{j}}=$ beta of stock $j$, assume stable over time

$\varepsilon_{\mathrm{j}, \mathrm{t}} \quad=\quad$ error term or return due to non-market forces (abnormal return).

Equation (1) is used to find the normal or expected returns. According to this model, each security's return in period $t$ is expressed as a linear function of the contemporaneous return on the market and a random error term $(\square \mathrm{j}, t)$ which reflects security specific returns.

The coefficients of the linear market model $(\alpha, \beta)$ are estimated by regressing observed rates of return for stock $\mathrm{j}$ on the corresponding rates of return for a market index. In computing these parameters daily, instead of monthly, data are used because price adjustments may occur within a few days after publication. Brown and Warner (1985) found that for daily returns the market model was most successful in identifying abnormal performance. ${ }^{2}$

We use GARCH model to improve the estimation accuracy. Since ordinary least squares (OLS) models assume homoscedasticity in the error terms. A growing body of literature indicates that many daily return series exhibit heteroscedasticity and the variance of the forecast error will depend on the size of the preceding disturbance. ${ }^{3}$ ARCH or GARCH models have been widely used to deal with this heteroscedasticity problem in the time series analysis. ${ }^{4}$

We collected the 200 daily returns for each recommended stock. Then, we divided the data into two time periods: the estimation period and the event window. The time line of whole sample period is denoted from $\mathrm{T}=-189$ to $\mathrm{T}=+10$. We estimated market model parameters over the estimation period beginning $\mathrm{T}=-189$ through $\mathrm{T}=-11$. This yields an estimation period of 179 days. The event window period has twenty-one days from $\mathrm{T}=-10$ to $\mathrm{T}=+10$ including $\mathrm{T}=0$, the event day.

Assuming that the estimated parameters $\alpha$ and $\beta$ remain unchanged over our sample period, the expected return $\mathrm{E}\left(R_{\mathrm{j}, \mathrm{t}}\right)$ is computed for each stock over the event window, from $\mathrm{t}=-10$ to $\mathrm{t}=+10$.

$\mathrm{E}\left(\mathrm{R}_{\mathrm{j}, \mathrm{t}}\right)=\alpha_{\mathrm{j}}+\beta_{\mathrm{j}} \mathrm{R}_{\mathrm{m}, \mathrm{t}}$ 
The abnormal return $\left(A R_{\mathrm{j}, t}\right)$ of stock $j$ is defined as the deviation of each return on the stock $\mathrm{j}$ from its expected return, given the return earned by the market index during day $t$. Using estimation period data to estimate market model parameters and assuming that these parameters hold in the event-window, the abnormal returns in the event-window period are estimated as follows:

$\mathrm{A} R_{\mathrm{j}, \mathrm{t}}=R_{\mathrm{j}, \mathrm{t}}-\mathrm{E}\left(\mathrm{R}_{\mathrm{j}, \mathrm{t}}\right), \quad$ or $\quad \mathrm{A} R_{\mathrm{j}, \mathrm{t}}=R_{\mathrm{j}, \mathrm{t}}-\left(\alpha_{\mathrm{j}}+\beta_{\mathrm{j}} \mathrm{R}_{\mathrm{m}, \mathrm{t}}\right)$

Where $R_{\mathrm{j}, \mathrm{t}}$ and $R_{\mathrm{m}, \mathrm{t}}$ are the observed daily returns for security $j$ and the market index, respectively, on day $t$ during the event window.

If publication of share recommendations has no impact on the sample stocks, then on average, one would not expect any abnormal return:

$\mathrm{E}\left(\mathrm{A} R_{\mathrm{j}, \mathrm{t}}\right)=0$

Assuming the standard assumptions hold.

To determine the statistical significance of abnormal returns on any event day $t$ of stock $j$, we first compute the Standardized Prediction Error $\left(S P E_{\mathrm{j}, \mathrm{t}}\right)$, an approach originally proposed by Patell [1976], and popularized in the finance literature by Dodd and Warner [1983]. ${ }^{5}$ Next, we construct the test statistic $Z_{\mathrm{t}}$ for every day $t$ in the event window, for all $N$ stocks. $^{6}$ As the $S P E_{\mathrm{t}}$ for a particular event window day aggregates observations from different periods and across all sample stocks, unfavorable and favorable effects of confounding events may be offset.

Assuming that abnormal returns $\left(A R_{\mathrm{j}, \mathrm{t}}\right)$ are independently distributed and have a finite variance and that the publication of share recommendations does not lead to abnormal returns, the null hypothesis is that publication of share recommendations in CS has no systematic effect on recommended stocks' prices:

$H_{0}$ : publication of stock recommendations in CS has no statistically significant impact on stock price

$H_{1}$ : publication of stock recommendations in CS has a statistically-significant impact on stock price

We also investigate the true economic impact or permanence of the press recommendations to ascertain whether or not a 'self-fulfilling prophecy' effect exists. Additionally, we explore whether following press recommendations enable abnormal profits. We compute the average cumulative abnormal return $(A C A R)$ to analyze the aggregate effect of such published information in the days prior to publication to determine whether any 'leakage' occurs. $^{7}$

To ascertain abnormal cumulative return in the event window, we standardize each $A C A R$ and test for significance by computing the statistic $Z\left(t_{1}, t_{2}\right)$ or $Z_{\mathrm{ACAR}}$, assuming that abnormal returns during the estimation period are independently distributed and the distribution of the test statistics is standard normal. ${ }^{8}$

$Z_{\mathrm{SCPE}}$ or the test statistic for the sum of the standardized cumulative prediction errors [see: Henderson, (1990), pp. 298-9] calculates the sum of standardized residuals instead of the standardized sum of residuals. That means statistically significant but relatively small abnormal returns from a series with normally small residuals will have equal weight with statistically significant but larger abnormal returns from a series with normally larger residuals [Wijmenga (1990)]. This contrasts with the $Z_{\mathrm{ACAR}}$ in which relatively small abnormal returns are "swamped" by relatively large abnormal returns.

\section{Result Analyses}

To examine the impact of recommendations we first examine the average relative stock price unadjusted (for market changes) for the event window period from day -10 to day +10 . The results are shown in Figure 1. The relative price is defined as: 
(price on day $\mathrm{t}) /($ price on day -10$)$.

There are insignificant changes with small up and down in relative prices from day -9 and day -6 , indicating a random pattern of the stock price movements. From day -5 to day 1 relative prices stay above the 1 mark, indicating a strong stock price movement during that period. From the event day to day +2 , the relative stock prices are drifting down. On day +3 , there is big jump in relative price. The relative prices trend downward from day +4 to day +7 . From day +8 to day +10 the relative prices go upward back to the 1 mark, ending almost where it start from day -10 .

\section{Figure 1 \\ Relative Price over the Event Window Stock Recommendations in CS:1/01-12/01}

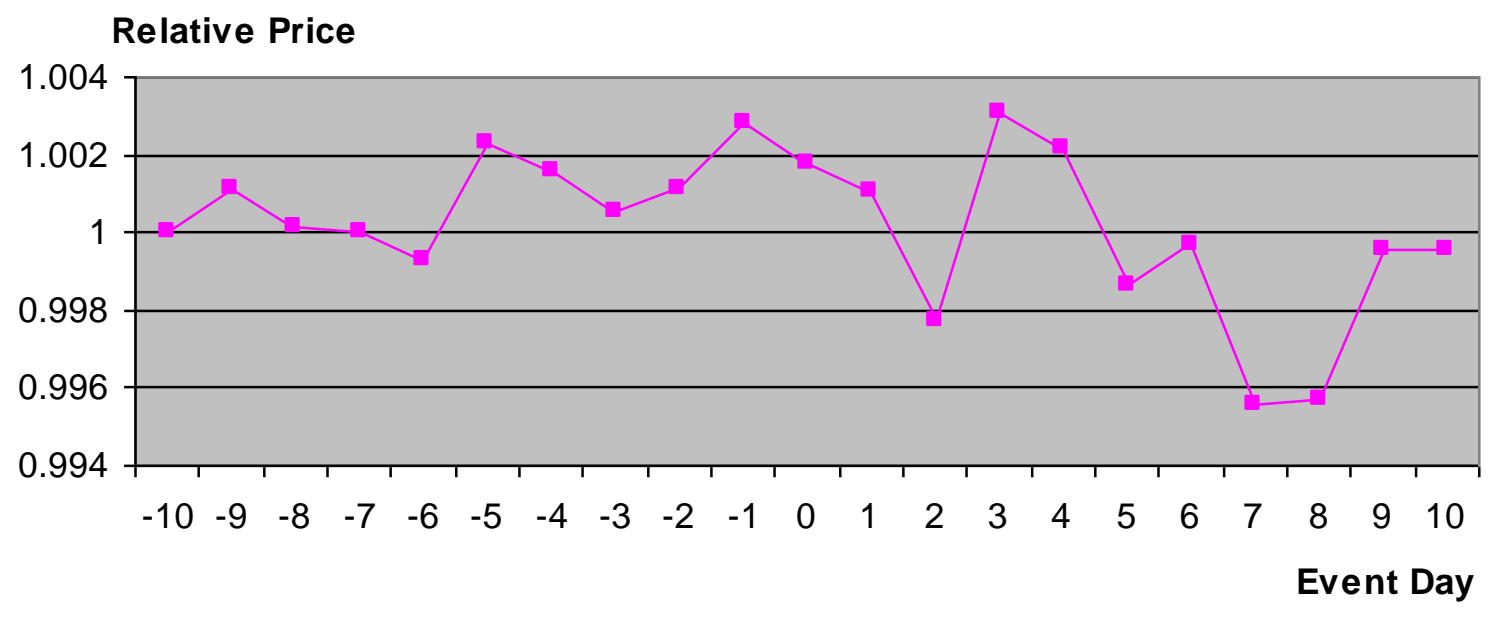

Relative price on day $t$ is defined as the ratio of the market price on day $t$ divided by the price on day -10 .

Figure 2 shows the average abnormal returns during the event window period. The big upward movement on day +3 confirms the similar movement in the relative price in Figure 1. The large abnormal return on day +3 suggests a delayed response from the investors who read the newspaper but do not act promptly. From day +4 to day +10 , the abnormal returns first trend downwards and then upwards, a similar pattern observed in Figure 1.

The delayed reaction from investors on day +3 illustrates that many investors will take some time to react to the stock recommendations because either they have access to the newspaper recommendation one or more days after the recommendation appear in the newspaper or they find impractical to engage in the daily trading as suggested in Barber, Lehavy, Mcnichols, and Trueman (2001). The evidence of delayed response from investors to analyst's recommendations is also documented in the finding of Stickel (1995) and Womack (1996).

To see if investors will earn abnormal return profits by following the newspaper recommendations we compute the average cumulative abnormal returns CAR. The results of cumulative abnormal returns are shown in Figure 3. From day -10 to day -1 , the period before the event day, the cumulative abnormal returns reach $3.26 \%$. From the event day to day +10 , the cumulative abnormal returns are $1.09 \%$ ( 4.35 on day +10 minus 3.26 on day -1 ).

We derive two conclusions from Figure 3: first, the average transaction costs in Chinese stock markets for a round trading are above one percent. Investors are unable to earn an abnormal return profit by buying the recommended stock on day 0 since the cumulative abnormal returns are around one percent from day 0 to day +10 ; Second, 
investors are able to make abnormal returns if they know the stock recommendation prior to the recommendation publication. If an investor buy the recommended stock from day -10 and hold it to the day +1 the cumulative abnormal returns are 4.07. On day +2 , a day after the event day, ACAR value falls, suggesting a price reversal. The evidence of price reversals is also documented in studies by Lloyd-Davies and Canes (1978), Wijmenga (1990), and Lawrence, Sun, and Cai (1996).

\section{Figure 2}

\section{Average Abnormal Return Over the Window Period Stock Recommendations in CS:1/01-12/01}

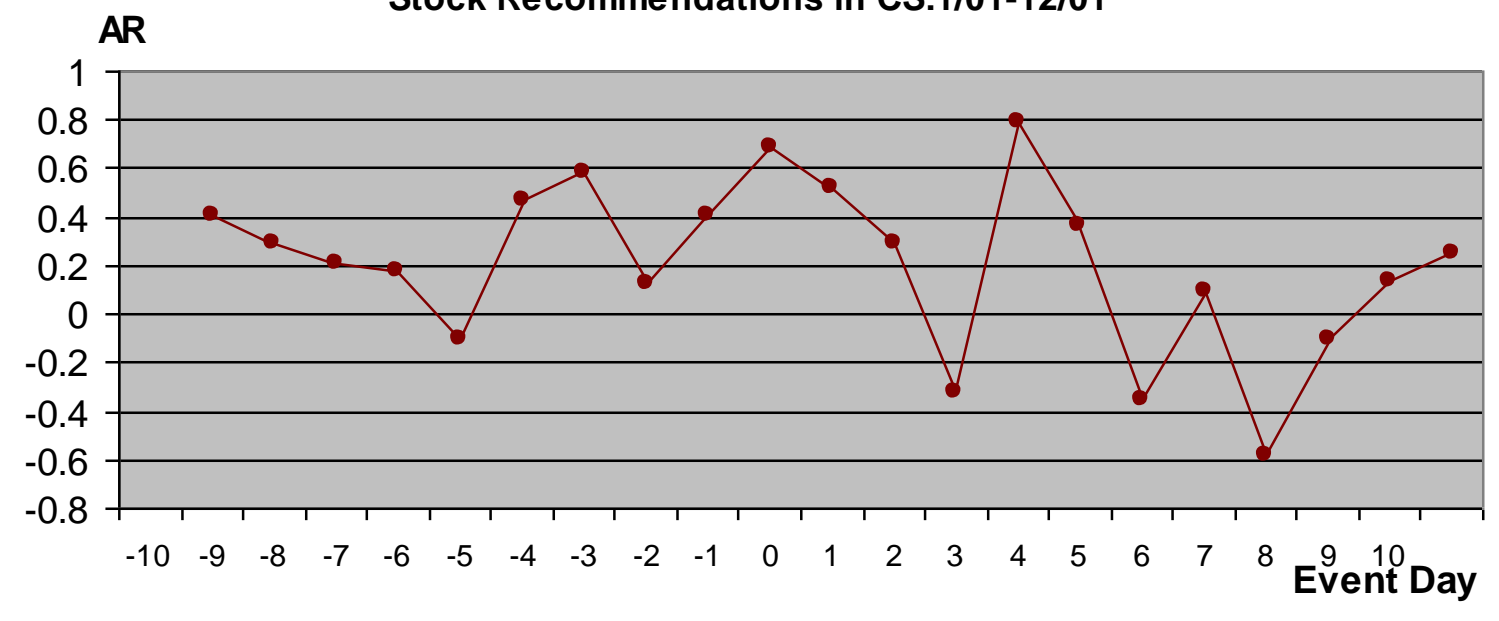

Abnormal return is defined as: $\mathrm{A} R_{\mathrm{j}, \mathrm{t}}=R_{\mathrm{j}, \mathrm{t}}-\left(\alpha_{\mathrm{j}}+\beta_{\mathrm{j}} \mathrm{R}_{\mathrm{m}, \mathrm{t}}\right)$

In order to draw a reliable conclusion we perform Z-tests for AAR and ACAR. The corresponding results are shown in Table 1. There are only one statistically significant AR on day +3 and one AR close to the $10 \%$ significant level on day -1 . There are no statistically significant CARs either before or after the event day, although CAR on day +4 is very close to the $10 \%$ significance level.

Lawrence, Sun, and Cai (1996) found in their study of the Singapore stock market that Clients of the brokerage firms may have acted on 'buy' recommendations prior to recommendation publication. The statistically significant $\mathrm{AR}$ in our paper on day -1 prior to the recommendation day shows some investors in Chinese stock markets are able to benefit from the recommendations before the recommendations are made public. This result suggests that the recommendations might be "leaked" to investors who act onthe

The significant AR on day +3 with $.787 \%$ doesn't warrant a profitable short term trading strategy based on the published recommendation. As mentioned above a round trading of buying and selling to take profit in Chinese stock markets would involve transactions amounting to commissions and taxes of above one percent. However, investors are able to make a short term abnormal return profit by buying the recommended stocks before the recommendations are published, a trading strategy that requires "insider information." Who are those possible profitable traders? They may be the clients of the brokerage houses that make the stock recommendations, or may be the people in the journal, or may be the people in the publication printing agency. The Z-value of 1.5637 for ACAR of $4.91 \%$ on day +4 is very close to ten percent significant level (or significant at $11.86 \%$ level.) From day 0 to day +4 the ACAR is $1.13 \%(4.91 \%$ (day +4$)-3.78$ (day 0$)$.) A strategy of buying the recommended stocks on day 0 after the recommendation is published does not yield a reliable abnormal return net of transaction costs. 


\section{Figure 3 \\ Cumulative Abnormal Returns over the Event Window \\ ACAR Stock Recommendations in CS:1/01-12/01}

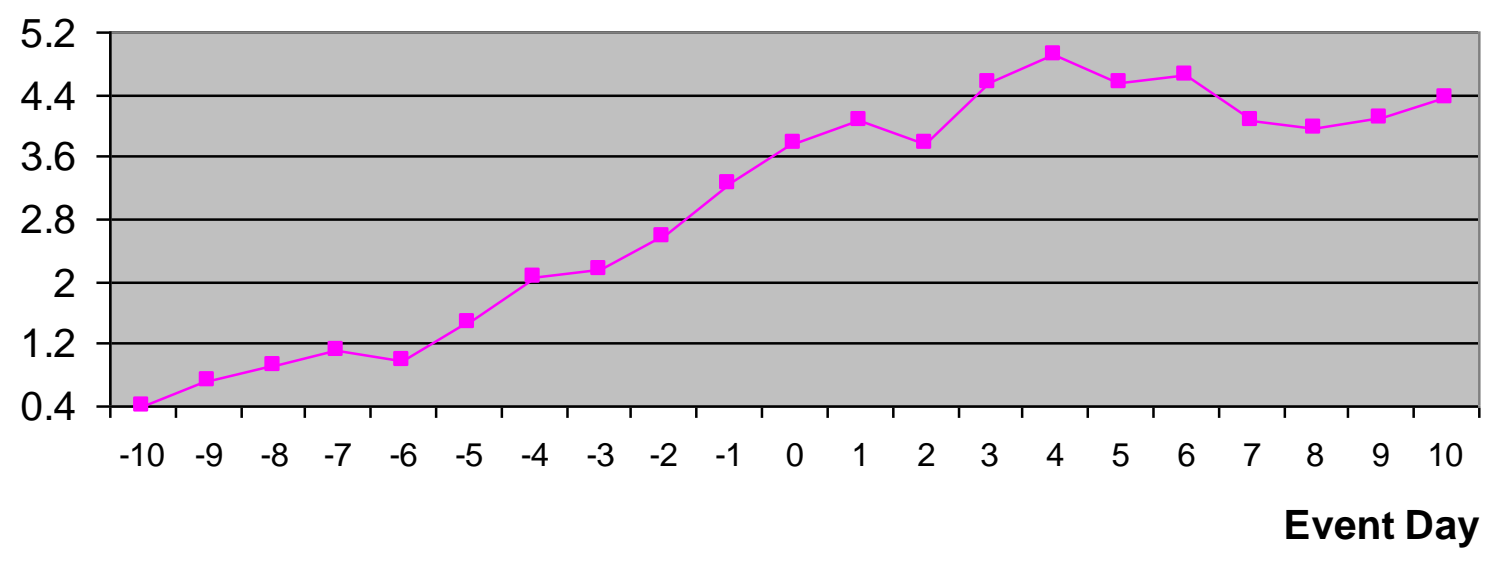

Cumulative abnormal return is defined as: $\mathrm{CA} R_{\mathrm{j}, \mathrm{t}}=\mathrm{CA} R_{\mathrm{j}, \mathrm{t}-1}+\mathrm{A} R_{\mathrm{j}, \mathrm{t}}$

\section{Summary and Conclusions}

In this paper, we have examined the impact of stock recommendations in a Chinese newspaper CS. This paper studies how the stock prices in Chinese stock markets react to the stock recommendations from a Chinese business newspaper Zhong Guo Zheng Quan Bao (China Security). Using event study methodology and market model as a benchmark, we calculate abnormal returns to ascertain the impact of published recommendations. We find that there are no statistically significant long-term abnormal returns associated with the published recommendations. However, there are profitable opportunities if investors act prior to the published recommendations.

We also find that the recommendations from the newspaper China Security causes a significant short term movement two days after the publication day, suggesting a delayed response from the investors who act on the recommendations. The delayed response shows the gradual dissemination of the information in Chinese stock markets. The delayed response of investors to the analysts' recommendations is consistent with the findings of price drift both in the US stock market as in Barber, Lehavy, Mcnichols, and Trueman (2001), Stickel (1995), and Womack (1996) and in the emerging stock markets such as Singapore stock market as in Lawrence, Sun, and Cai (1996).

In summary, these results indicate that press recommendations of Chinese stocks contain no useful economic information for investors who act on the published recommendations. The possible abnormal returns for investors who buy the stocks before the recommendations are made public are evidence of a market that is strong-form inefficient and the delayed responses from investors to the newspaper recommendations are most likely are the evidence of a market is semi-strong-form inefficient.

Several problems have emerged during our research that we have not attempted to solve. Some of them are mentioned below for further study in the future. (i) As has been discussed in the paper, there is a statistical evidence that the recommendations might be "leaked" to investors who act on them prior to the publication of the recommendations. The further research is needed to find out how the information is "leaked" - by the journalists? or by the 
Table 1: AAR (\%), ACAR (\%) and Corresponding Z-Statistics for the Sample over the Event Window

\begin{tabular}{|c|c|c|c|c|}
\hline$\overline{\text { Day }}$ & AAR & Z-Value & ACAR & Z-Value \\
\hline-10 & 0.411553 & 0.987728 & 0.411553 & 0.107004 \\
\hline-9 & 0.297332 & 0.749276 & 0.708885 & 0.185728 \\
\hline-8 & 0.210325 & 0.555257 & 0.91921 & 0.242671 \\
\hline-7 & 0.180847 & 0.484669 & 1.100056 & 0.294815 \\
\hline-6 & -0.10761 & -0.30991 & 0.992448 & 0.263991 \\
\hline-5 & 0.469546 & 1.108128 & 1.461993 & 0.394738 \\
\hline-4 & 0.579553 & 1.32138 & 2.041546 & 0.5553 \\
\hline-3 & 0.12509 & 0.345247 & 2.166635 & 0.593658 \\
\hline-2 & 0.405101 & 0.988445 & 2.571736 & 0.709799 \\
\hline-1 & 0.687888 & $1.5487 \approx$ & 3.259624 & 0.906176 \\
\hline 0 & 0.523829 & 1.215283 & 3.783453 & 1.066934 \\
\hline 1 & 0.296101 & 0.758018 & 4.079554 & 1.174911 \\
\hline 2 & -0.31983 & -0.9339 & 3.759725 & 1.052723 \\
\hline 3 & 0.787187 & $1.83182 *$ & 4.546912 & 1.336792 \\
\hline 4 & 0.363711 & 0.902004 & 4.910623 & $1.57387^{*} \approx$ \\
\hline 5 & -0.35144 & -1.04027 & 4.55918 & 1.349517 \\
\hline 6 & 0.092326 & 0.258513 & 4.651506 & 1.386149 \\
\hline 7 & -0.58497 & -1.46243 & 4.066536 & 1.163029 \\
\hline 8 & -0.10134 & -0.28782 & 3.965192 & 1.126115 \\
\hline 9 & 0.139913 & 0.380564 & 4.105106 & 1.190481 \\
\hline 10 & 0.24787 & 0.644462 & 4.352976 & 1.271069 \\
\hline
\end{tabular}

* significant at $10 \%$ level.

$* \approx$ significant at $12 \%$ level.

analysts themselves. (ii) The sample of 120 recommendations is not considered too small for a research in an emerging stock market. However, a larger sample will certainly help us to gain additional statistical insights into the emerging market behavior. (iii) We have investigated the impact of buy recommendations on the stock price behavior. What about sell recommendations? Do sell recommendations have the similar impacts as buy recommendations? Whether the results we have obtained here are robust to, different data sources, different kinds of recommendations is left to the future work.

\section{References}

1. Barber, Brad M., Lehavy, Mcnichols, and Trueman, 2001, Security analyst recommendations and stock returns, Journal of Finance, 56, 533-563

2. Bjerring, J. H., J. Lakonishok and T. Vermaelen, 1983, Stock prices and financial analysts recommendations, Journal of Finance 38, 187-204.

3. Bollerslev, T., R. Chou and K. Kroner, 1992, ARCH modeling in finance, Journal of Econometrics 52, 5-59.

4. Brown, S. J. and J. B. Warner, 1980, Measuring security price performance, Journal of Financial Economics 8, 205-258.

5. Dimson, E. and P. Marsh, 1986, Event study methodologies and the size effect: the case of UK press recommendations, Journal of Financial Economics 17, 113-142.

6. Dimson, E. and P. Marsh, 1984, An analysis of brokers' and analysts' unpublished forecasts of UK stock returns, Journal of Finance 39, 1257-1292.

7. Lawrence, Martin, Qian Sun and Francis Cai, 1996, Press recommendations and abnormal returns on the stock exchange of Singapore, The Journal of International Finance, Volume 4, Number 2, 149-163

8. Liu, P., S. D. Smith and A. A. Syed, 1990, Stock price reactions to the Wall Street Journal's securities recommendations, Journal of Financial and Quantitative Analysis 25, 399-410.

9. Lloyd-Davies, P. and M. Canes, 1978, Stock prices and the publication of second-hand information, Journal of Business 51 43-56. 
10. Pagan, A., 1996, The econometrics of financial markets, Journal of Empirical Finance 3, 15-102.

11. Palmon, O., H. L. Sun and A. P. Tang, 1994, The impact of publication of analysts' recommendations on returns and trading volume, Financial Review 29, 395-417.

12. Stickel, Scott E., 1995, The anatomy of the performance of buy and sell recommendations, Financial Analysts Journal 51, 25-39.

13. Zivney, T. L. and D. J. Thompson II, 1989, The specification and power of the sign test in measuring security price performance: comments and analysis, The Financial.

\section{Endnotes}

1 Investment bankers and brokerage houses spend a great amount of money on security analysis, presumably because these firms and their clients believe its use can generate abnormal returns.

2 Our study does not take into account the effect of non-synchronicity inherent in daily data. Studies by Brown and Warner (BW) (1985) indicated ignoring this factor does not result in the misspecification of event study methodologies using OLS regression. Daily data may mean non-normality in returns. However, BW (1985) found that mean excess returns in a cross section of securities converges to normality as the portfolio size increases. For our portfolio of 69 stocks, we assume the return distribution is normal. BW also demonstrated that adjustments for autocorrelations in daily data do not significantly change results.

3 See, for example: Engle (1982), Kryzanowski and Zhang (1993), Bollerslev, Chou, and Kroner (1991), Baillie and DeGennaro (1989), Pagan (1996), and Lawrence, Sun, and Cai (1996).

4 Please see Bollerslev, T., R. Chou and K. Kroner (1992) for its use in finance research.

5 See, also: Patell and Wolfson (1979).

6 See: Henderson (1990), p. 299.

7 See, for example: Henderson (1990), p. 297.

8 The test statistics employed follow: Lawrence, Sun, and Cai (1996). 